
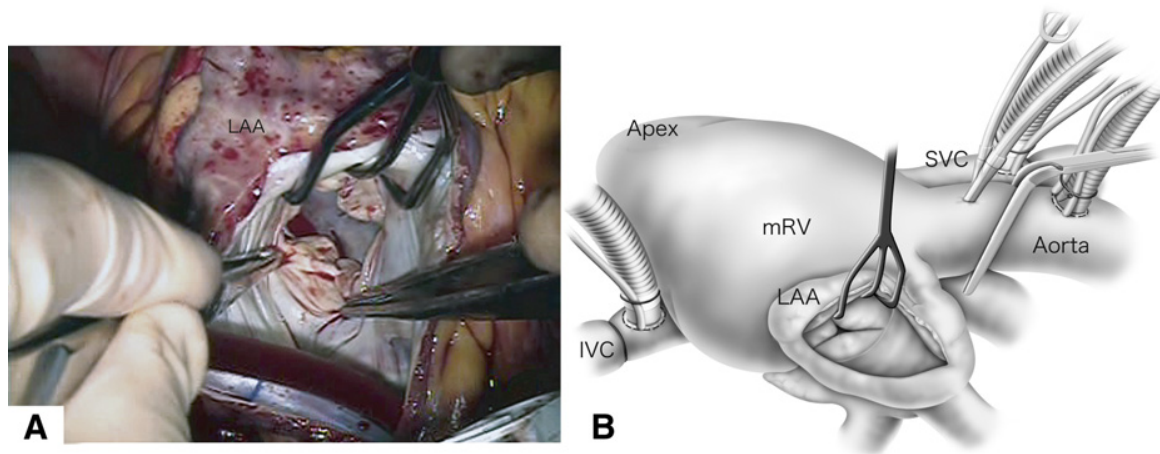

FIGURE 2. Intraoperative view (A) and sketch (B) taken from the patient's left side showing annular dilatation of the systemic tricuspid valve. $m R V$, Morphologically right ventricle; $I V C$, inferior vena cava; $S V C$, superior vena cava; $L A A$, left atrial appendage.

\section{DISCUSSION}

In patients with CCTGA, TR increases and mRV dysfunction often develops progressively with time. ${ }^{1}$ There is a close relationship between TR and $\mathrm{mRV}$ dysfunction, leading to congestive heart failure. ${ }^{2}$ Van Son and associates $^{3}$ reported an association between $\mathrm{mRV}$ dysfunction with an ejection fraction of less than $44 \%$ and poor early and late prognosis, even after surgery. On the basis of this report, it may have been too late for surgery in our patient, but she is currently doing well. Possible reasons for her good recovery include the following: (1) welldeveloped papillary muscles were preserved in the TV; (2) the MV regurgitation was repaired; and (3) the chronic atrial fibrillation was eliminated with the Cox maze procedure.
Situs solitus CCTGA with dextrocardia is very uncommon, but it influences all technical aspects of the surgical procedure, from cannulation to exposure of both atrioventricular valves. In such rare cases, the TV can be replaced via the left atrial appendage from the left side of the patient, while the $\mathrm{MV}$ is repaired from the right side by lifting the apex during aortic crossclamping.

\section{References}

1. Prieto LR, Hordof AJ, Secic M. Progressive tricuspid valve disease in patients with congenitally corrected transposition of the great arteries. Circulation. 1998;98:997-1005.

2. Graham TP Jr, Bernard YD, Mellen BG. Long-term outcome in congenitally corrected transposition of the great arteries: a multi-institutional study. JAm Coll Cardiol. 2000;36:255-61.

3. Van Son JA, Danielson GK, Huhta JC. Late results of systemic atrioventricular valve replacement in corrected transposition. J Thorac Cardiovasc Surg. 1995; 109:642-52.

\title{
Migration of retained right ventricular epicardial pacing wire into the pulmonary artery: A rare complication after heart surgery
}

\author{
Patrick J. Worth, BA, Patrick Conklin, MD, Ethan Prince, MD, and Arun K. Singh, MD, FRCS(C), \\ Providence, RI
}

Temporary atrial and ventricular epicardial pacing wires have been routinely placed after cardiac surgery to diagnose and treat arrhythmia, and assist in optimizing hemodynamics. $^{1}$ These wires are routinely removed from

\footnotetext{
From the Division of Thoracic and Cardiovascular Surgery and Department of Radiology, The Warren Alpert Medical School of Brown University, Rhode Island Hospital, Providence, RI

Disclosures: Authors have nothing to disclose with regard to commercial support. Received for publication April 27, 2010; accepted for publication May 24, 2010; available ahead of print July 1, 2011.

Address for reprints: Arun K. Singh, MD, Two Dudley St, Providence, RI 02905 (E-mail: asingh@lifespan.org).

J Thorac Cardiovasc Surg 2011;142:e136-8

0022-5223/\$36.00

Copyright (c) 2011 by The American Association for Thoracic Surgery doi:10.1016/j.jtcvs.2010.05.058
}

patients before discharge; however, they are occasionally cut at skin level and allowed to retract into the pericardial sac when they cannot be removed. Rare complications may occur from retained wires. ${ }^{1}$ We observed one such complication of a migrated epicardial pacing wire found in the right ventricle extending to the pulmonary artery giving rise to shortness of breath.

\section{CLINICAL SUMMARY}

A 65-year-old man was admitted to the hospital for progressive bilateral lower-extremity swelling, weakness, and urinary retention. His medical history was significant for myocardial infarction, hypercholesterolemia, ischemic colitis, and peripheral vascular disease with arterial stenosis in 


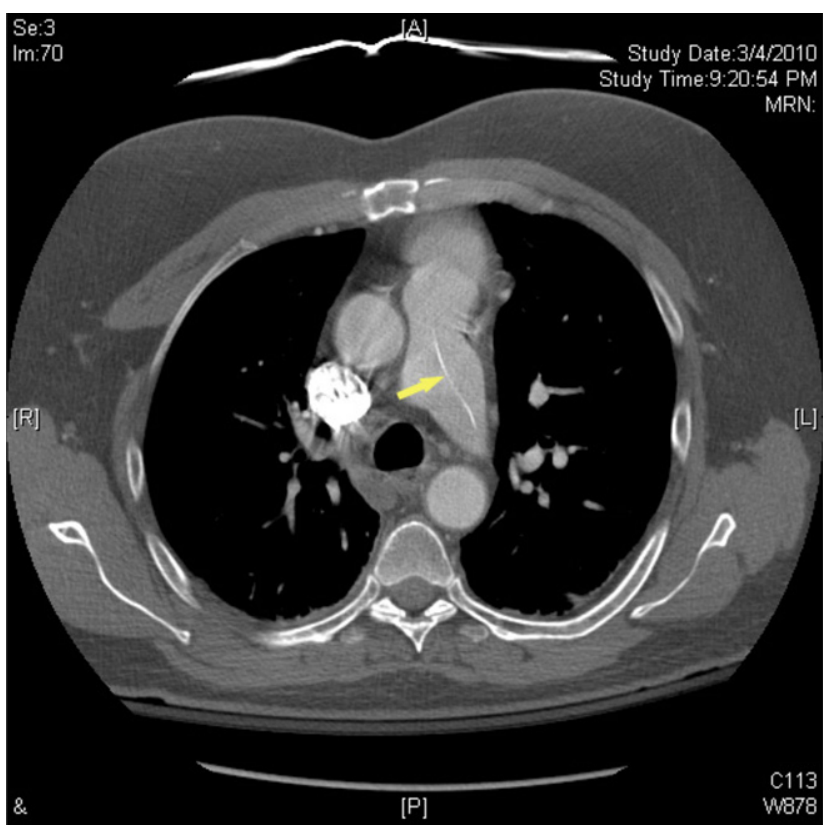

FIGURE 1. Linear opacity (arrow) noted on computed tomography angiography for ruling out pulmonary embolus. There is no evidence of thrombus or obstruction of flow associated with opacity.

his left lower extremity. He underwent uneventful 3-vessel coronary artery bypass grafting in 1986 . On discharge, right ventricular epicardial pacing wires were cut at the level of skin after an unsuccessful attempt to remove with gentle traction and allowed to retract subcutaneously.

At presentation, he was found to be febrile to $102.3^{\circ} \mathrm{F}$, with a leukocytosis of 14,600 cells $/ \mathrm{mL}^{3}$ ( $1 \%$ bands). Blood cultures were negative. Urinalysis revealed a urinary tract infection, and ciprofloxacin was administered. His physical examination results were unremarkable except for bilateral lower-extremity edema. Left lower-extremity ultrasound was negative for deep venous thrombosis.

On hospital day 2, the patient had shortness of breath. He was found to be tachypneic and wheezing, and was initially treated with a combination ipratropium/albuterol nebulizer with symptomatic relief. On examination, he was found to have a blood oxygen saturation of $93 \%$ on room air; his physical examination results were within normal limits. In light of the patient's presentation, examination, and reduced mobility, he was sent for computed tomography angiography to rule out pulmonary embolus.

Computed tomography angiography revealed no evidence of acute embolic process and a linear opacity (Figure 1) in the left pulmonary artery originating in the right ventricle and terminating in a proximal branch of the left pulmonary artery. The linear opacity did not appear to be causing disruption of flow, nor was it thought to be associated with visible thrombus. Because of the concern of further migration, infection, and perforation of lung parenchyma, we elected to remove the foreign body.

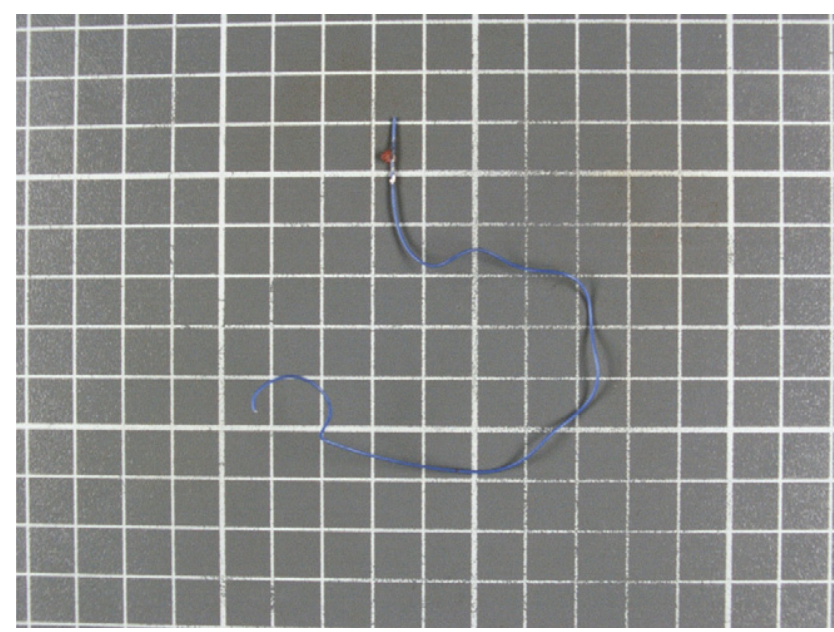

FIGURE 2. Gross pathologic image of migrated retained transcutaneous epicardial pacing wire (17.5 cm in length) removed by vascular interventional radiology.

With the use of fluoroscopic guidance, the right femoral vein was cannulated and the wire was extracted from the right ventricle and pulmonary artery using a $35-\mathrm{mm}$ Amplatz gooseneck snare (AGA Medical Corp, Plymouth, Minn). The foreign body was sent to pathology and determined to be a $18-\mathrm{cm}$ segment of a retained transcutaneous epicardial pacing wire (Ethicon, Inc, Somerville, NJ; Figure 2), which had been inserted 24 years previously when the patient underwent coronary artery bypass grafting. The cardiothoracic surgeon who had performed the procedure was consulted and further corroborated the identity of the pacing wire. After extraction, the patient had an uneventful recovery; cultures of the wire showed negative results.

\section{DISCUSSION}

The value of intraoperative placement of temporary pacing wires was initially appreciated in tetralogy of Fallot and ventricular septal defect repairs, but was translated to the establishment and maintenance of "stable cardiac rhythms" and optimum cardiac function postoperatively in patients undergoing cardiac surgery. ${ }^{1}$ Still, despite being a largely beneficial therapeutic, diagnostic intervention, the temporary placement of transcutaneous epicardial pacing wires is not without complication. In 1989, Del Nido and Goldman ${ }^{2}$ reported on frequent complications associated with temporary pacing wires, including failure of sensing/capture, perforation, dislodgement, and retention. They encouraged gentle traction as a strategy for removal of these wires, which are frequently cut at the level of the skin if they are unable to be removed by traction.

It is not clear when the pacing wire became lodged in the pulmonary artery in this case. If it was an acute process during this hospitalization, one cannot be entirely certain that the movement of the wire caused the shortness of 
breath and wheezing. Indeed, it could have been an entirely coincidental series of events that led to the identification and removal of the pacing wire. The significance of this event is in the fact that this wire was found in the right ventricle and pulmonary artery after its placement in the epicardium after coronary artery bypass grafting 24 years previously.

Several case reports have been published pertaining to complications from retained epicardial wire migration. Korompai and colleagues ${ }^{3}$ first reported a case of migrated temporary pacing wire found in the peritoneal cavity in 1987, thought to be retained after cardiac surgery that had been performed 6 years previously. Three years after surgery, Meier and colleagues ${ }^{4}$ reported a case of ventricular tachycardia and cardiac arrest associated with erosion of an epicardial pacing wire through the right atrium. Juchem and colleagues ${ }^{5}$ reported a patient who had undergone mitral valve replacement 2 years previously; aortic and mitral prosthetic valve endocarditis developed secondary to infected pacing wire coursing from the aortic bulb to the right carotid artery.

\section{CONCLUSIONS}

Migration is a well-established albeit rare complication of retained temporary pacing wires, with a variety of clinical effects. The exact mechanism as to how the wire dislodged into the heart is unknown, but it may be a result of constant movement of the heart and diaphragm. We describe the most remote complication of retained pacer wires to date, diagnosed 24 years from placement. The retention of cardiac pacing wires should be communicated to all physicians responsible for the patient's care because it could lead to issues many decades after surgery.

\section{References}

1. Reade MC. Temporary epicardial pacing after cardiac surgery: a practical review. Anaesthesia. 2007;62:264-71.

2. Del Nido P, Goldman BS. Temporary epicardial pacing after open heart surgery: complications and prevention. J Card Surg. 1989;4:99-103.

3. Korompai FL, Hayward RH, Knight WL. Migration of temporary epicardial pacer wire fragment retained after a cardiac operation. J Thorac Cardiovasc Surg. 1987; 94:446-7.

4. Meier DJ, Tamirisa KP, Eitzman DT. Ventricular tachycardia associated with transmyocardial migration of an epicardial pacing wire. Ann Thorac Surg. 2004; 77:1077-9.

5. Juchem G, Golczyk K, Kopf C, Reichart B, Lamm P. Europace. 2008;10:1348-9.

\title{
A new era: Use of an intracorporeal systemic ventricular assist device to support a patient with a failing Fontan circulation
}

\author{
David L. S. Morales, MD, Iki Adachi, MD, Jeffrey S. Heinle, MD, and Charles D. Fraser, Jr, MD, Houston, Tex
}

Worldwide experience with ventricular assist device (VAD) support in patients with univentricular physiology has been very limited. In particular, the use of a long-term continuous-flow implantable VAD has never been described. We report the successful application of an intracorporeal systemic ventricular assist device (SVAD), the HeartMate II (Thoratec Corporation, Pleasanton, Calif), in an adolescent with a failing Fontan circulation and protein-losing enteropathy (PLE).

\section{CLINICAL SUMMARY}

The patient is a 15-year-old boy (body surface area, $1.5 \mathrm{~m}^{2}$ ) with double-outlet right ventricle, mitral atresia,

\footnotetext{
From the Congenital Heart Surgery Division, Texas Children's Hospital, Michael E. DeBakey Department of Surgery, Baylor College of Medicine, Houston, Tex. Disclosures: Authors have nothing to disclose with regard to commercial support. Received for publication Dec 17, 2010; revisions received April 18, 2011; accepted for publication May 23, 2011; available ahead of print July 15, 2011.

Address for reprints: David L. S. Morales, MD, Division of Congenital Heart Surgery,

Texas Children's Hospital, 6621 Fannin St, WT19345H, Houston, TX 77030

(E-mail: dlmorale@texaschildrens.org).

J Thorac Cardiovasc Surg 2011;142:e138-40

$0022-5223 / \$ 36.00$

Copyright (c) 2011 by The American Association for Thoracic Surgery doi:10.1016/j.jtcvs.2011.05.018
}

and a systemic right ventricle. He underwent staged palliation culminating in a fenestrated lateral Fontan operation at 3 years old. Although he did well for many years, his condition began to deteriorate with increasing dyspnea on exertion, peripheral pitting edema, and hepatomegaly with ascites. PLE was diagnosed (serum albumin, $2.6 \mathrm{~g} / \mathrm{dL}$; prealbumin, $9.7 \mathrm{mg} / \mathrm{dL}$ ). Echocardiogram revealed severely depressed systolic ventricular function with significant tricuspid regurgitation. In preparation for cardiac transplantation, a cardiac catheterization was performed. After induction of positive-pressure ventilation, he had several periods of cardiac arrest necessitating resuscitation. The abbreviated catheterization demonstrated a severely elevated Fontan pressure of $30 \mathrm{~mm} \mathrm{Hg}$, a pulmonary vascular resistance of 1.9 Wood units, normal caliber pulmonary arteries, and a wedge pressure of $22 \mathrm{~mm} \mathrm{Hg}$. Because his circulatory failure was primarily the result of systemic ventricular dysfunction and his condition was hemodynamically unstable, he underwent urgent VAD placement.

Because the patient had levocardia with normally related great arteries, a HeartMate II SVAD was implanted in the usual manner (Figure 1) on cardiopulmonary bypass without cardiac arrest. The only atypical aspect was the 